\title{
What could make islanders use a new public transport system? Identifying the determinants of the intention to use a new Reserved Public Transport Lane in the urban area of Fort-de- France, Martinique
}

\section{Valérie Fointiat}

Aix Marseille univ, LPS, Aix en Provence, France

valerie.fointiat@univ-amu.fr

\section{Marie Feliot-Rippeault}

Université des Antilles, Pôle Martinique, Biosphères, France

marie.feliot-rippeault@univ-antilles.fr

\begin{abstract}
In 2015, Fort-de-France, the main city of Martinique, a small French West Indies island, made the ambitious decision to introduce a new mode of public transportation, a reserved public transport lane, or 'RPTL'. Based on the Technology Acceptance Model, we conducted a survey to identify the determinants of intention to use the new mode of transport by current public transport users on the island. These determinants seem to vary depending on the frequency of use of the current transport system. Hence, when people already used public transport every day (high frequency), their intention to use the RPTL is solely predicted by the perceived usefulness of the RPTL. For those who use it less often (moderate frequency), only the norm-i.e., what others do-and age were predictors of intention to use the RPTL. Finally, for rare public transport users (low frequency), their intention is predicted by perceived usefulness and social norms. These results show that all users have different reasons for using this new mode of transport. Identifying these determinants could be useful to local politicians, enabling them to make efficient information and promotion campaigns for the RPTL, and especially designed for those potential users who are not familiar with public transport.
\end{abstract}

Keywords: islands, Martinique, mobility, public transport system, Reserved Transport Public Lane, urban area

https://doi.org/10.24043/isj.102 • Received December 2018, accepted July 2019

C 2019-Institute of Island Studies, University of Prince Edward Island, Canada.

\section{Martinique: A small island in the French West Indies}

Based on the criterion defined by McElroy and de Albuquerque (1998), Martinique is a small volcanic island of 1,228 square kilometres in area and 397,357 in population (estimated at the beginning of 2018). Gil et al. (2011) have also pointed out the limitations of small islands; that 
is, their geographical parameters of smallness, remoteness and isolation. Like the other French Caribbean islands of Guadeloupe and Saint-Martin (shared with Netherlands), Martinique is 7,000 kilometres from mainland France.

The narrow stretch of land is 65 kilometres long and reaches a maximum width of 30 kilometres. As shown in Figure 1, the mountainous terrain in the north contains volcanic massifs and a tropical forest. The majority of tourism infrastructures are located in the south of the island. Main economic activity is concentrated in the centre of the island, especially around the capital city of Fort-de-France. This is also where the highest population density can be found, i.e., almost $37 \%$ of the total population. As a result, most jobs (that is, about half of the total jobs on the island according to the French Institute of Statistics and Economics/INSEE, 2016) are concentrated in Fort-de-France and its conurbation, including Schoelcher and Le Lamentin.

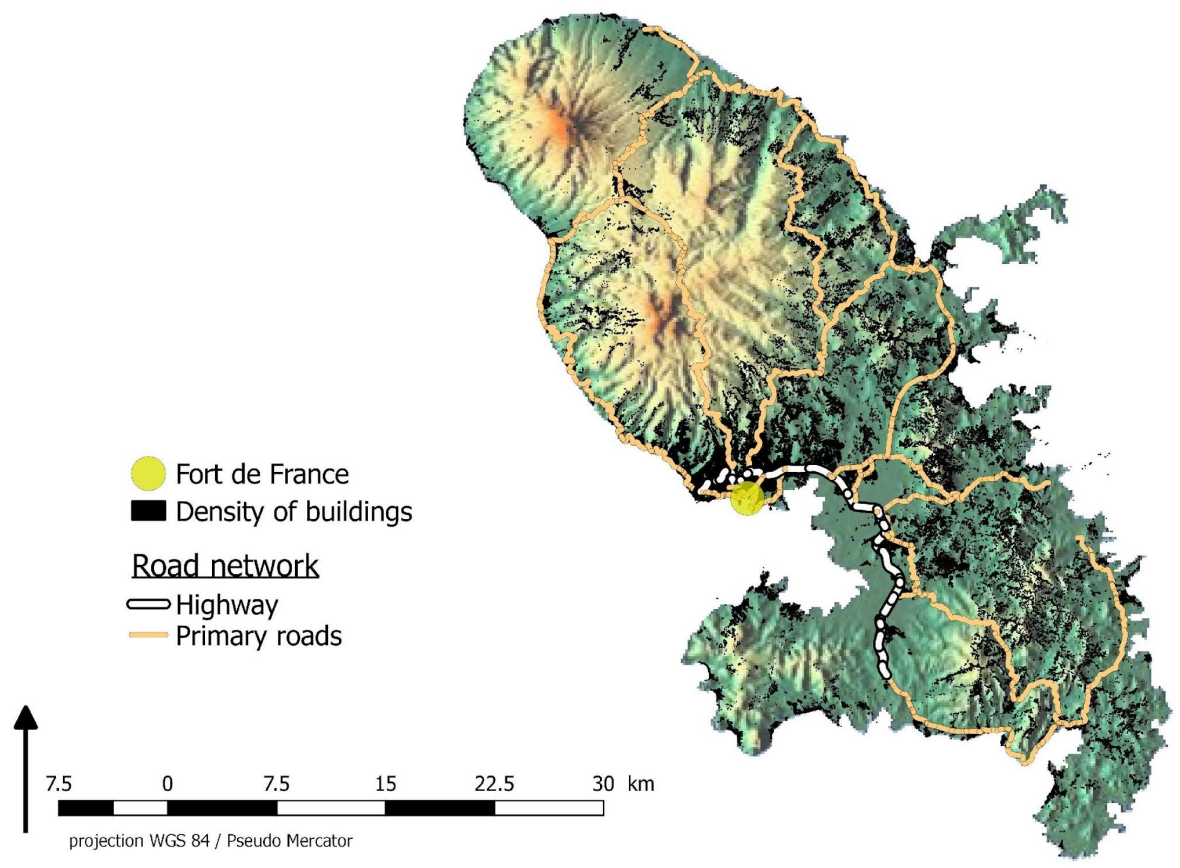

Figure 1: Martinique Island, including relief, road network, primary road, and density of buildings. Source: (C) Sascha Perroux, 2018.

The morpho-geological features of the island, combined with a highly concentrated economic activity zone and high population density, has led to a congested road network around the Fort-de-France conurbation.

\section{Mobility in Martinique: More and more cars}

The spatial organization of urban traffic flow is concentrated around several main trunk roads (see Figure 1). Environmental constraints combined with the use of private cars increases traffic congestion around the urban area of the Fort-de-France conurbation linking the commercial and industrial zones in the south of the island to the economic capital. Adding to this is the weakness of the public transport system, which heightens the use of private cars, especially from 
home to workplace itineraries; $56 \%$ of workers work away from their place of residence (INSEE/French Institute of Statistics and Economics, 2016). Daily traffic flow reaches 122,000 vehicles per day at the entrance to the Fort-de-France conurbation (Observatoire Territorial des Transports en Martinique, 2018). This flow is equivalent to traffic flow recorded for large French cities with populations five times higher. In addition there are clear indications that the south demographic trends will lead to higher numbers of journeys towards the centre and especially to Fort-de-France.

In 2018, the ratio was approximately one car for every two inhabitants on the island, i.e., 203,525 cars for 386,874 inhabitants. This figure is higher than on mainland France where during the same period the ratio was 1 car for every 1.7 inhabitants (INSEE / French Institute of Statistics and Economics, 2010). The negative effects of the increasingly accelerating use of private cars have been described by many researchers (Taniguchi et al, 2014). Several of them have underlined the consequences: increased emissions (Chapman, 2007) and increased congestion (Greene \& Wegener, 1997) directly due to increased car travel. Additionally, the number of workers using their cars seems to be on the increase: the percentage of workers using their own car to drive to work continues to increase, whereas at the same time public transport usage is decreasing: $8.3 \%$ of workers used public transport in 2015, compared to $9.1 \%$ in 2010 and 14\% in 1999 (INSEE /French Institute of Statistics and Economics, 2016).

Road traffic congestion and especially of private cars would also result from the weak supply of the public transport network. For a long time, several public transport networks have coexisted on the island: urban transport (collective buses) and intercity passenger transport also called 'taxicos', leading to a lack of coordination on tariffs and lines served. Since July 2017, Martinique Transport has become the unique interlocutor of transport and mobility.

\section{An innovative mode of transport: The reserved public transport lane-RTPL}

Due to the saturation of the main trunk roads on the island and in response to inhabitants' concerns, the Martinique public authorities have promoted an innovative public transport system as one of their main objectives; that is, the reserved public transport lane RPTL (translated from French TCSP as Transport Collectif en Site Propre). In the long term this mode of transport will offer an alternative to private cars, as it will provide a link between the industrial, commercial and employment areas of Fort-de-France and its conurbation. This ambitious project for a rapid transport lane will provide a safe, environmentally friendly mode of transport, which will not be affected by problems of traffic congestion. Initially, the RPTL was to be inaugurated on January 1, 2016. Successive delays led to an official launch in August 2018, followed by strike actions that prevented regular service until now.

Ranély Vergé-Dépré (2012) had already highlighted the territorial issues which the RPTL represented in 2011, especially the economic and environmental stakes. Based on development policy planning she foresaw that the RPTL could transport 55,750 passengers daily; that is, 14.6 million passengers per year. According to these estimations, $60 \%$ of these passengers would be previous users of standard public transport, $37 \%$ would be previous car users and $6 \%$ would be users encouraged by a gain in mobility.

Reducing the number of cars in circulation by implementing the RPTL is put forward as one of the means of fighting against the large number of harmful effects generated by motorized 
vehicles: air pollution, noise, water pollution, etc. However, local policy has tried for several years to develop and encourage changes in public transport usage without much success. The local authorities therefore have underlying worries as to the appropriation of the RTPL by the inhabitants.

It is within this context that we carried out a survey of the island's inhabitants. From our point of view, it could be helpful to identify the determinants of the intention to use the RPTL, a new public transport, presented by public policies as a tool to reduce traffic congestion and greenhouse gas emissions. We used the theoretical model of the Technology Acceptance Model as a guideline.

\section{Technology acceptance model}

The technology acceptance model (TAM) (Davis et al, 1989) was initially conceived to understand the acceptance of information and communication technologies. It has since been applied to several other technologies or services, including eco-friendly transportation systems by private households (Chen \& Lu, 2016) or the acceptance of electric vehicles (Globisch et al, 2018).

The TAM is based on two main constructs: the perceived usefulness and the perceived ease of use. These two constructs predict the attitude towards the technology or the service, which in turn predicts the behavioural intention to use it. Some authors have added social influence and frequency of past behaviours, or habit (Venkatesh et al, 2003).

Perceived usefulness and perceived ease of use

Perceived usefulness refers to the extent to which the users believe that using a technology or a service will enhance her/his performance. Perceived ease of use refers to the extent to which the users believe that using the technology or the tool will require no physical or mental effort (or at least very little effort). The construct perceived usefulness is more important than the perceived ease of use on the behavioural intention to use. The reason is simple: The users need to perceive the object or the service as useful. Failing that, they will not even try to use it, regardless of how easy or difficult it is to use. Thus, ease of use is less important because difficulty in using an object (or a system) can be overcome if the user thinks that the service will be useful to her/him. These two variables can therefore affect intention to use the RTPL.

Attitude towards use and social influence

Attitude could be defined as the positive or negative evaluation of an object or a behaviour (Mathieson, 1991) or the service. For Ajzen \& Fishbein (2005), the attitude towards a specific behaviour determines whether the behaviour is performed. The attitude towards the RTPL can affect intention to use it.

Insofar as we are working on an island population for whom the opinion of people close to them is of particular importance (Pogdorelec et al, 2015), we included social influence, and specifically a measure of social norms. Social norms refer to an individual's beliefs about whether other people, who are perceived as crucial, want the individual to perform a certain behaviour. There is a long tradition in social psychology showing the impact of social norms on the behaviour of individuals (Cialdini \& Goldstein, 2004). It turns out that social norms and more 
specifically the descriptive (what most people do) and injunctive (what most people approve or disapprove) dimensions are guides to behaviour.

Hence, the way in which a person imagines how the others (those who are important to them) assess the RPTL would no doubt affect their own intention to use it.

\section{Frequency of past behaviours}

Long-standing research has shown that what we do today guides what we do tomorrow. In other words, our past behaviours are good predictors of future behaviours. Habits have been amply studied in the domain of eco-friendly behaviours (Ouellette \& Wood, 1998; Verplanken $\&$ Roy, 2016). The frequency of actual use of public transport will enable us to assess the force of habit, knowing that the stronger it is the better it will predict future behaviour. We would expect the actual use of the current public transport system to be a good predictor of intention to use the RTPL when it starts running.

\section{Survey}

The survey was conducted at five different bus stops of the future RPTL: Sainte-Therese, Galleria, Pointe Simon, Mahault and Airport, which currently serve the public transport stops and which will become stops for the new RTPL route. The survey was run in December 2015, one month before the official launch, set for January 1, 2016. Of the total number of participants $(\mathrm{N}=222), 171$ responded fully to the questionnaire, giving a satisfactory response rate of $77 \%$.

The questionnaire consisted of three parts. In part 1, items illustrated the different dimensions of the technology acceptance model, such as perceived use, ease of use, social influence, attitude and intention to use the RPTL. Part 2 focuses on the use of public transport. Participants provided information on how often they use public transport. They were also asked to state the reasons why they use public transport. Part 3 of the questionnaire included sociodemographic information.

Part 1: Technology acceptance measures

For each of the following measures, respondents reported to what extent they agree or disagree on a five-point Likert scale, from 1 totally disagree to 5 totally agree. The descriptive statistics are presented in Table 1.

Perceived usefulness. The items were the following: "RPTL will enable me to have a safe journey," "RPTL will be useful," "RPTL will mean no parking problems" and "RPTL will enable me to reach my destination rapidly." As Cronbach alpha was satisfactory $(\alpha=.746)$, the items were aggregated into an index of perceived usefulness.

Ease of use. The respondents reported their degree of agreement for each of the three items: "Information about RPTL is easy to find," "the stops are well reported" and "the RPTL will be easy to use." As the Cronbach alpha was satisfactory $(\mathrm{a}=.55)$, an index of ease of use was constructed.

Attitude towards the RPTL. We used a semantic differential including ten bipolar adjectives (Osgood, 1952). Thus, the respondents had to report how much they perceived the RTPL as complicated-practical, expensive-cheap, dangerous-safe, unpleasant-pleasant, late-on time, slow-fast, uncomfortable-comfortable, unattractive-attractive, old fashioned-modern, polluting-ecological. A factor analysis (varimax rotation) conducted on the ten items of the 
measure produced a two-factor solution, explaining $51.83 \%$ of the total variance. The sample's factor score adequacy is satisfactory $(\mathrm{KMO}=.865)$ and Bartlett's test is significant $(p<.001)$. The first factor was made up of the items dangerous-safe, unpleasant-pleasant, slow-fast, uncomfortable-comfortable, unattractive-attractive, old fashioned-modern, polluting-ecological (respective scores, .498, .701, .714, .731, .658, .739, .557, $\alpha=.83$ ). This first factor explains $41.23 \%$ of the total variance and referred to the hedonic evaluation of the RTPL. The second factor explained $10.6 \%$ of the variance and included expensive-cheap and late-on time (respective scores, .887 and $.641, r=.395, p<.01$ ). This factor referred to the cost evaluation (money and time) of the RTPL. One item (complicated-practical) loaded on both factors and was excluded. Attitude towards the RTPL proves to be made up of two dimensions. Thus two indexes were constructed, as reported in Table 1.

Social influence. The items were the following: People who are important to me/my family / my relations, will use the RTPL, people who are important to me think I should use the RTPL and for most of the people who are important to me, the RPTL is a good thing. As Cronbach alpha was satisfactory $(\alpha=.76)$, the data were aggregated into an index.

Behavioural intention. A single-item measured the intention to use the RTPL: "I am going to use the RTPL as soon as it starts running."

Table 1: Descriptive statistics of the measures.

\begin{tabular}{|l|l|l|l|l|l|}
\hline & $\begin{array}{l}\text { Number } \\
\text { of items }\end{array}$ & $\begin{array}{l}\text { Cronbach } \\
\text { alpha/ } \mathrm{r}^{\mathrm{a}}\end{array}$ & Mean & SD & Minimum-maximum \\
\hline Perceived usefulness & 4 & .746 & 3.273 & 1.054 & $1-5$ \\
\hline Ease of use & 3 & .546 & 3.159 & .808 & $1-5$ \\
\hline Social influence & 3 & .765 & 2.889 & 1.200 & $1-5$ \\
\hline Hedonic evaluation & 7 & .828 & 1.983 & .787 & $1-5$ \\
\hline Evaluation of cost & 2 & $.395^{\mathrm{a}}$ & 2.667 & .879 & $1-5$ \\
\hline Intention to use RPTL & 1 & & 2.46 & 1.423 & $1-5$ \\
\hline
\end{tabular}

N.B. PT: public transport; ${ }^{a} \mathrm{r}$ is used when only two items composed the index.

\section{Part 2: Actual use of public transport}

The frequency of actual use was measured through a single item such as "I use local public transport." The respondents chose one of the five possibilities: daily (coded 1); often (one to three times a week, coded 2); from time to time (one to three times a month, coded 3); occasionally (one to three times a year, coded 4); and never (coded 5).

\section{Part 3: Sample characteristics}

In the last part of the questionnaire, respondents reported their gender, age, usual mode of transport, reasons for using public transports, income and where they lived.

The usual mode of transport was evaluated through a multiple-choice question ("I usually travel by a) car; b) car-pooling; c) two wheeled motorized vehicle; d) bicycle; e) public transport; f) walking"). The reasons for using public transport were collected on a single closed-ended item ("When I use local public transport, it's to a) get to work; b) go shopping; c) travel around; d) other"). The respondents reported their income on a single item ("Taking into account that the average net income in Martinique is $1,400 €$, your income is ...") on a 7-point Likert scale 
ranging from 1: much lower than average to $7:$ much higher than average. Finally, information on where they lived was collected on a single item ("Do you live ...") on a 5-point Likert scale ranging from 1 in very rural area/countryside to 5 very urban area/city centre.

\section{Results}

After presenting the sample characteristics, we will present the determinants of intention to use the RTPL on the overall sample and, examine the determinants, taking into account the frequency of the actual use of public transport.

\subsection{Sample characteristics}

Half of the sample is women $(49.7 \%)$. The mean age is $36.49(S D=16.53)$. Concerning the usual mode of transport, participants indicated that they used public transport and private cars for their journeys, representing respectively $59.6 \%$ and $34.3 \%$ of the choices. When asked the reasons for actually using public transport, "to get to work" was the first one (62.7\%); a lot less for "to go shopping" (16.4\%) or "to travel around" (16.4\%). With regard to income, $21.1 \%$ of the participants reported an average income, compared with $31.6 \%$ reporting a lower than average income and $21.1 \%$ a higher than average income. Finally, 32.2\% of the respondents indicated that they lived in a rural area, $18.7 \%$ in a peri-urban area and $42.7 \%$ in an urban area.

Determinants of the intention to use RTPL among the overall sample

First of all, we checked the influence of age, income, place of residence and gender on intention to use the RTPL. Age predicts the intention $(\beta=.394, t=5.53, \mathrm{p}<.000)$. On the other hand, neither income, nor places of residence, predict the intention (respectively $\beta=.09, t=1.02, p>.20$, et $\beta$ $=.10, t=1.28, p>.20)$. The influence of gender is not observed either $\left(M_{\text {Women }}=2.85, S D=1.71\right.$, $95 \%$ CI $[2.47,3.22]$ and $M_{\text {Men }}=2.56, S D=1.69,95 \%$ CI $[2.20,2.92], F(1,170)=1.22$, ns).

In line with identifying the determinants of the intention to use the RPTL, a first multiple regression (forced entry method) was run on the overall sample $(N=171)$. We included the components of the technology acceptance model (perceived usefulness, ease of use, social norms, hedonic evaluation and evaluation of cost) as predictors of intention. Past behaviour has been included through the reported actual frequency of public transport. We also included age.

This model explains $45 \%$ of the total variance $\left(\mathrm{R}=.45\right.$, Adjusted $\left.\mathrm{R}^{2}=.43\right)$. If the seven variables contribute to the model, only four out of the seven predict intention to use the RPTL: social norms, age, perceived usefulness and frequency of public transport use.

As predicted in the specific context of small islands like Martinique, the social norm is a predictor of the intention to use a new public transport $(\beta=.36, t=4.72, p<.001)$. In the same way, the older the respondents, the more they report a strong intention to use the RPTL ( $\beta=$ $.271, t=4.257, p<.001)$. Not surprisingly, the more the respondents perceive the future RPTL as useful, the higher their intention is to use it $(\beta=.195, t=2.47, p<.01)$. Finally, the actual frequency of public transport use predicts the intention to use the new one in a near future ( $\beta$ $=.251, t=4.07, p<.001)$.

This latest result reinforces previous results (Verplanken \& Roy, 2016), that is, past behaviours are good predictors of future behaviours. In the next series of analyses, we have split the overall sample according to the frequency of use of public transport. 
Determinants of the intention to use the RTPL according to frequency of use of public transport Respondents who reported using public transport daily were assigned to the first group (high frequency group, $n=62$ ). Respondents who reported a moderate use of public transport-that is, one to three times a week to one to three times a month-were assigned to the second group (moderate frequency group, $n=58$ ). Respondents who reported to use public transport one to three times a year, or never, were assigned to the third group (low frequency group, $n=51$ ).

First of all, there was no difference in age between the three groups $\left(M_{\text {high freq. }}=36.69, S D\right.$ $\left.=15.883, M_{\text {moderate freq. }}=36.33, S D=18.215, M_{\text {low freq. }}=36.42, S D=15.579\right)$. Moreover, a oneway ANOVA shows a significant effect of the frequency of actual use of public transport on the intention to use the RTPL (respectively $M_{\text {high freq. }}=3.18, S D=1.73, M_{\text {moderate freq. }}=2.88, S D=$ $\left.1.69, M_{\text {low freq. }}=1.92, S D=1.38, \mathrm{~F}(2,169)=8.91, \mathrm{p}<.001\right)$.

We ran a series of regression analyses on each of the three groups. The predictors are the same as previously, except the frequency of public transport use. The results are summarized in Table 2 .

Table 2: Synthesis of the regression analyses (entry method).

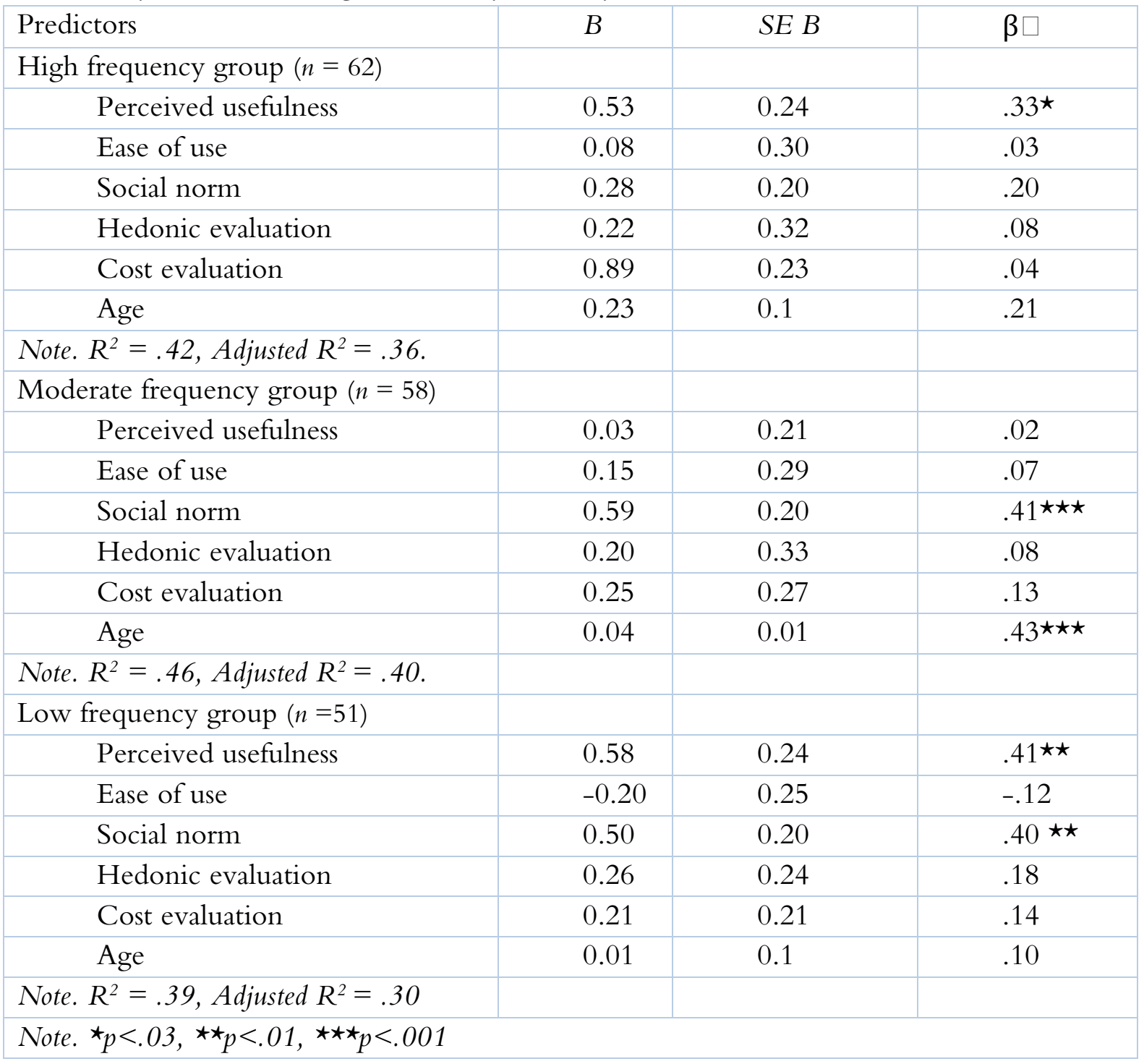


With regard to the high frequency group, the model explains $42 \%$ of the variance, which is satisfactory. This first group is the one that indicated using the current public transport system (e.g., the bus) daily. These participants are used to using Martinique's public transport. All the variables are part of the model, but only perceived usefulness predicts intention to use the new mode of transport $(\beta=.33, p<.03)$. In other words, current public transport users, already used to using public transport, intend to use the RTPL as soon as they perceive its usefulness.

As far as the moderate frequency group is concerned, the model explains $46 \%$ of the total variance. The users from this group use public transport much less frequently than those in the previous group (between one to three times a week and one to three times a month). Even if they are not regular town bus users they know the bus service and use it. For this group of users, their intention to use the new RTPL is predicted by two factors: social norm and age (respectively $\beta=.41, \mathrm{p}<.001$ and $\beta=.43, \mathrm{p}<.001$ ). In other words, their intention depends on what others (i.e., those who are important to them) think of the RTPL. Intention to use the RTPL also increases according to the users' age. These two factors also weigh on intention in comparable proportions.

As for the users group that used public transport very rarely-that is, one to three times per year, or less-the model explains 39\% of total variance. The proportion of the variance explained is weaker than in the other two previous models, but is quite acceptable. For these users, their intention is predicted by perceived usefulness and social norm (respectively $\beta=.41$, $\mathrm{p}<.01$ and $\beta=.40, \mathrm{p}<.01)$. Intention to use the RTPL would therefore depend on how useful the RTPL would be to them and the opinions of those important to them.

\section{Discussion}

When considering just the total sample $(\mathrm{N}=171)$, without taking into account the level of use of public transport, the model explained $45 \%$ of the overall model's variance. This first result is in line with those of Davis et al (1989) who showed that their model explained $47 \%$ of total variance. The results obtained here are consistent with the literature. In addition our results show that the model could be extended to the total population, the Adjusted $\mathrm{R}^{2}$ (Adj. $\mathrm{R}^{2}=.43$ ) being very close to $\mathrm{R}^{2}$.

Taking into account the level of usage of current public transport, it appears that intention to use the RPTL is predicted by different factors. For regular public transport users (high frequency group), only perceived usefulness predicts intention. The main reason put forward by this population for using public transport is "to get to work." We thus understand that for regular users of town buses, changing to the RTPL depends on the usefulness attributed to this mode of transport. They have already developed the habit of using public transport. Hence there is nothing surprising in their intention to continue to use public transport even with the proposed new offer of the RTPL. This first result is directly in line with previous research (Verplanken \& Roy, 2016) showing that past behaviours (here, the use of public transport) are good predictors of future behaviours (here, using the RTPL). Indeed, provided they perceive the usefulness of the RTPL, there are no particular obstacles to their intention to use it. As for the respondents who hardly ever use public transport (low frequency group), it is interesting to note that both perceived usefulness and the social norm are predictors of intention to use the 
RTPL. They have to perceive and understand the added value that the RTPL represents, and be surrounded by close friends and relatives who endorse using the RTPL, to consider using it.

For both these populations, the construct "perceived usefulness" is more important than the perceived ease of use on the actual use. The reason is simple: the users need to perceive the object as useful. Failing that, they won't even try to use it, regardless of how easy or difficult it is to use. On the whole our results comply with the previously obtained ones: perceived usefulness prevails over ease of use.

On the other hand, this weight of perceived usefulness disappeared for users already using public transport, albeit moderately (moderate frequency group). For them social norms prevailed over perceived usefulness: what their families and friends think and say about the RTPL has more weight on their intention to use-or not-than the usefulness they attribute to it.. These results are echoed by the literature. Some studies on the relationship of islanders and particularly small-island inhabitants have shown that the main point for islanders is the quality of a self-other relationship (Podgorelec et al, 2015). These authors have shown that small-island inhabitants were particularly concerned with their image and worry about what other people think of them. Thus, we expect the social norm to be of importance. In the case of Martinique, the weight of social norms on behaviour could be reinforced by a historical sense of inferiority, due to their legacy of slavery (Lirus, 2000). Age is also a predictor of intention to use the RTPL. In other words, in this sub-sample, the older the people are, the more likely they are to use the RTPL. It is the only group of our study for which age predicts intention to use the RTPL. Consequently, as generations of Martinicans are very impregnated in their social relationships as a whole, it is possible that other people's opinions count more as they increase in age: the older people become, the more other people's opinions on the RTPL influence their intention to use it or not. To put it in other words, faced with something new, the older the people are the more they would seek social support as a basis for their own intention.

\section{Limits and perspectives}

A first limit concerns the relatively low sample size. It must be emphasized that our sample consisted of people waiting for the bus. Also, as soon as the bus arrived, they would get in, whether the questionnaire was complete or not. From this point of view, our sample was not captive.

A second limit concerns the special relationship the inhabitants of Martinique have with their car. As we have already underlined, journeys could be motivated by several factors, such as, studies, personal business and leisure; but the main reason for travelling is to get from home to work. Hence, Ranély Vergé-Dépré (2012), based on a source from the French Institute of Statistics and Economics, underline that $79 \%$ of workers use their car to get to their workplace, and this figure was constantly increasing. This almost exclusive use of the car could also come from the social markers the car provides on the island, as a symbol of freedom and social success. This positive perception of the car is reinforced by the negative perception of the public transport system in terms of the network, frequency and fares-and even safety. Future research would benefit from a more in-depth study of the relationship of the islanders with their car. This would provide a better understanding of the symbolic issues which could be hidden mobility constraints. 
A third limit concerns the lack of measurement of actual use of the RTPL. As noticed below, the survey was conducted in December 2015. At the time it was to be a month before the RTPL started running. We planned to carry out a second phase of the survey a month after the RTPL was put into service. This second phase is necessary not only for assessing the model's validity but especially to better understand the determinants of acceptability once the system was operating.

Postponing the opening of the RTPL in 2015-despite the fact that the infrastructures had been completed and inaugurated-damaged credibility in public policies and affected the perception of the new mode of transport. Public opinion harshly criticized this postponement; yet our results show that the opinion of others on a social object (here the RPTL), as well as perceived usefulness, are important determinants in intention to use it. The RTPL started running in August 2018, so we plan to carry on with our study by focusing on perception of this new mode of transport and the determinants of its actual usage. This next survey will enable us to study the level of appropriation of this mobility option.

Communication actions adapted to users according to their actual usage frequency of public transport could take our results into account by targeting especially those whose usage frequency is moderate, i.e., those people using their cars and public transport. Indeed, our results show that they are the most sensitive to opinions circulating and socially shared about the RTPL, and, consequently, the most sensitive to information campaigns.

\section{Acknowledgements}

We would like to thank Sascha Perroux for her precious help with the map of Martinique and the anonymous reviewers for their helpful comments and suggestions.

\section{References}

Ajzen, I., \& Fishbein, M. (2005). The influence of attitudes on behavior. In D. Albarracín, B. T. Johnson, \& M. P. Zanna (Eds.), The handbook of attitudes (pp. 173-221). Mahwah: Erlbaum.

Chapman, L. (2007). Transport and climate change: A review. Journal of Transport Geography, $15,354-367$.

Chen, S. Y., \& Lu, C. C. (2016). Exploring the relationships of green perceived value, the diffusion of innovations, and the technology acceptance model of green transportation. Transportation Journal, 55, 51-77. https://doi.org/10.5325/transportationj.55.1.0051

Cialdini, R. B., \& Goldstein, N. J. (2004). Social influence: Conformity and compliance. Annual Review of Psychology, 55, 591-621. https://doi.org/10.1146/annurev.psych.55.090902.142015

Davis, F. D., Bagozzi, R. P., \& Warshaw, P. R. (1989). User acceptance of computer technology: A comparison of two theoretical models. Management Science, 35, 982-1003. https://doi.org/10.1287/mnsc.35.8.982

Gil, A., Calado, H., \& Bentz, J. (2011). Public participation in municipal transport planning processes: The case of the sustainable mobility plan of Ponta Delgada, Azores, Portugal. Journal of Transport Geography, 19, 1309-1319. https://doi.org/10.1016/j.jtrangeo.2011.06.010

Globisch, J., Dütschke, E., \& Schleich, J. (2018). Acceptance of electric passenger cars in commercial fleets. Transportation Research Part A, 116, 122-129. https://doi.org/10.1016/j.tra.2018.06.004 
Greene, D. L., \& Wegener, M. (1997). Sustainable transport. Journal of Transport Geography, 5, 177-190.

INSEE (2016). Déplacements domicile-travail: une intensification des déplacements domiciletravail en Martinique. INSEE. Retrieved from https://www.insee.fr/fr/statistiques/2019762

Lirus, J. (2000). Identité Antillaise. Contribution à la connaissance psychologique et anthropologique des Guadeloupéens et Martiniquais. Paris: Editions Caribéennes.

Mathieson, K. (1991). Predicting user intentions: Comparing the technology acceptance model with the theory of planned behavior. Information Systems Research, 2, 173-191. https://doi.org/10.1287/isre.2.3.173

McElroy, J. M., \& de Albuquerque, K. (1998). Tourism penetration index in small Caribbean Islands. Annals of Tourism Research, 25, 143-168. https://doi.org/10.1016/s0160$\underline{7383(97) 00068-6}$

Observatoire Territorial des Transports de Martinique (2018). Retrieved from http://www.observatoire-transports-martinique.com/

Osgood, C. E. (1952). The nature and measurement of meaning. Psychological Bulletin, 49, 197-237.

Ouellette, J. A., \&, Wood, W. (1998). Habit and intention in everyday life: The multiple processes by which past behaviour predicts future behaviour. Psychological Bulletin, 124, 54-74. https://doi.org/10.1037/0033-2909.124.1.54

Podgorelec, S., Gregurovic, M., \& Klempić Bogadi, S. (2015). Satisfaction with the quality of life on Croatian small islands: Zlarin, Kaprije and Žirje. Island Studies Journal, 10, 91-110.

Ranély Vergé-Dépré, C. (2012). Territorial stakes of "TCSP " of Martinique. Revue Géographique de l'Est, 52, 1-17.

Taniguchi, A., Grääs, C., \& Friman, M. (2014). Satisfaction with travel, goal achievement, and voluntary behavioral change. Transportation Research Part F, 26, 10-17. https://doi.org/10.1016/j.trf.2014.06.004

Venkatesh, V., Morris, M. G., Davis, G. B., \& Davis, F. D. (2003). User acceptance of information technology: Toward a unified view. MIS Quarterly: Management Information Systems, 27, 425-478. https://doi.org/10.2307/30036540

Verplanken, B., \& Roy, D. (2016). Empowering interventions to promote sustainable lifestyles: Testing the habit discontinuity hypothesis in a field experiment. Journal of Environmental Psychology, 45, 127-134. https://doi.org/10.1016/j.jenvp.2015.11.008 